Original Research Article

\title{
Drug utilization study in otorhinolaryngology outpatient department in a tertiary care teaching hospital
}

\author{
Sumalatha R.*, Nagabushan H., Hanumanth Prasad M.
}

Department of Pharmacology, Mandya Institute of Medical Sciences, Mandya, Karnataka, India

Received: 01 January 2017

Accepted: 02 February 2017

\section{*Correspondence to:}

Dr. Sumalatha R.,

Email:

drsumalathar24@gmail.com

Copyright: (C) the author(s), publisher and licensee Medip Academy. This is an openaccess article distributed under the terms of the Creative Commons Attribution NonCommercial License, which permits unrestricted noncommercial use, distribution, and reproduction in any medium, provided the original work is properly cited.

\begin{abstract}
Background: Drug utilization research is defined by the World Health Organization (WHO) as marketing, distribution, prescription, and use of drugs in society, with special emphasis on the resulting medical, social, and economic consequences. Drug utilization study identifies the problems that arise from prescription and highlights the current approaches to the rational use of drugs. The main aim of the study is to assess the pattern of drug usage and the rationality of drug use in Otorhinolaryngology out-patient department (OPD).

Methods: A prospective observational study was conducted in the OPD of Otorhinolaryngology at tertiary care hospital, Mandya, Karnataka, over a period of one year. Prescriptions of all OPD patients were collected, relevant information entered in a specially designed proforma and analysed using descriptive statistics.

Results: A total of 21058 drugs were prescribed out of 8028 prescriptions. Majority of the patients were male $(51 \%)$. Antimicrobials were the most commonly prescribed drugs (28\%), followed by antihistamines (25\%), antipyretics (20.5\%).Most of the drugs $18576(88.2 \%)$ were prescribed by oral route, followed by topical route. Majority of the drugs were prescribed by the generic names $(86.5 \%)$. Most common type of infection was ear infection (3176), followed by throat infection (2848) and nose infection (2004).

Conclusions: The present study showed that among antimicrobial agents, $\beta$ lactams were commonly prescribed drugs in the department of Otorhinolaryngology. The maximum number of cases was diagnosed with ear infections and majority of the drugs were prescribed orally.
\end{abstract}

Keywords: Drug utilization, Otorhinolaryngology, Prescription pattern

\section{INTRODUCTION}

Drug utilization studies are used as potential tools in the evaluation of health care systems. Drug utilization research is an essential part of pharmacoepidemiology as it describes the extent, nature and determinants of drug exposure. ${ }^{1}$ Drug utilization research is defined by the World Health Organization (WHO) as the "marketing, distribution, prescription and use of drugs in society with special emphasis on the resulting medical, social, and economic consequences." 2

Studies on the process of drug utilization focus on the factors related to prescribing, dispensing, administering and consumption of medication, and its associated events, covering the medical and non-medical determinants of drug utilization and the effects of drug utilization. ${ }^{3}$

The International Network for the Rational Use of Drugs (INRUD) was established in 1989 to promote the rational use of drugs in developing countries. ${ }^{4}$ A rational prescription establishes a good doctor patient relationship which in turn translates into better patient compliance. ${ }^{5}$ The important criteria for rational drug use are accurate diagnosis, proper prescribing, correct dispensing, suitable packing and patient adherence. ${ }^{6}$

Ear, nose and throat infections (ENT) are most common diseases, which affect majority of the population. ${ }^{7}$ These infections are generally caused by microorganisms viz bacteria, fungi and viruses and accordingly the treatment 
involves the use of appropriate antimicrobials. Most of the respiratory tract infections (RTIs) are viral in origin, common organism being respiratory syncytial virus, which do not require use of antimicrobials as they resolve spontaneously. ${ }^{8}$

However antibiotics become necessary when the respiratory tract infections are complicated by secondary infections such as lower respiratory tract infection, acute tonsillitis, sinusitis, and acute otitis media with effusion. Majority of the studies have shown that most of the antibiotics were prescribed for infections especially of viral etiology, such as rhino-pharyngitis and acute bronchitis. ${ }^{9}$ The problem of overuse of antimicrobials is often a global phenomenon. ${ }^{10}$

Increased cost of medical care, antimicrobial resistance, adverse effects and patient morbidity are due to inappropriate use of drugs. ${ }^{11}$

It is important to monitor and evaluate the drug utilization patterns from time to time, to enable suitable alterations in prescribing patterns to increase the therapeutic benefit and to reduce adverse effects. ${ }^{12}$ There is more concern about inappropriate and expensive prescribing than under-prescribing. ${ }^{13}$

The infecting organisms and their antimicrobial susceptibility differ from country to country and also from region to region, since there is wide variation in antimicrobial prescription due to the factors like physician preference, local policy, cost and lack of local guidelines. ${ }^{14}$

Because of complexity of drug use, optimal drug benefits may not be derived due to possible underuse, overuse and misuse of drugs. ${ }^{15}$

Drug utilization studies are used to review the prescriptions that are prescribed to the patient. It helps to give the feedback to clinicians so that they can develop protocol for optimal drug use and also can educate the patients to use the appropriate drug. ${ }^{16}$

Hence, this study will help us to generate up to date information on drug usage in Otorhinolaryngology outpatient department, indications and aptness of drug use.

\section{Study objectives}

To assess the pattern of drug usage and rationality of drug use in Otorhinolaryngology outpatient department.

\section{METHODS}

A prospective observational study was initiated after the approval from Institutional Ethics Committee, Mandya Institute of Medical Sciences, Mandya. Drug utilization study was conducted at outpatient Department of
Otorhinolaryngology, tertiary care hospital, Mandya, Karnataka over a period of one year.

\section{Inclusion criteria}

- $\quad$ Patients attending ENT OPD and giving consent

\section{Exclusion criteria}

- Inpatients and follow up visit patients

- $\quad$ Surgical patients

- Seriously sick patients

Patient's relevant information was entered in predesigned proforma and analyzed. Patients details such as age, gender, diagnosis and drugs prescribed were recorded. The following drug utilization indicators were assessed:

a) Average number of drugs prescribed per patient.

b) Percentage of encounters with an antibacterial prescribed.

c) Percentage of encounters with an antihistamine prescribed.

d) Percentage of encounters with an antipyretic and analgesic prescribed.

e) Percentage of drugs prescribed by generic name.

f) Percentage of drugs prescribed by different routes.

Statistical analysis: The collected data was analysed using SPSS software version 20. 2015. Results were expressed in terms of percentage.

\section{RESULTS}

A total of 8028 prescriptions were analysed, majority of patients were between the age group of 18 to 40 years (35.4\%), followed by 41 to 65 years $(25 \%)$, less than 18 years $(18.8 \%)$ and the least were in age group of 66 years and above (4.2\%) (Table 1).

Table 1: Age distribution.

\begin{tabular}{|lll|}
\hline Age (in years) & Number & Percentage (\%) \\
\hline$<18$ & 1513 & $18.8 \%$ \\
\hline $18-40$ & 4142 & $51.6 \%$ \\
\hline $41-65$ & 2043 & $25.4 \%$ \\
\hline$>66$ & 330 & $4.2 \%$ \\
\hline Total & $\mathbf{8 0 2 8}$ & $\mathbf{1 0 0}$ \\
\hline
\end{tabular}

Our study shows, male patients were 4019 (51\%) and female were 4009 (49\%). Overall drugs prescribed among 8028 prescriptions were 21058. Most of the drugs $18576(88.2 \%)$ were prescribed by oral route followed by topical route $2482(10.5 \%)$ and parenteral route was 274 $(1.3 \%)$ (Figure 1).

In our study, prescription index was found to be 2.6. Drugs were prescribed in the range of 1-4 drugs per prescription. Minimum prescribed drug was 1 and 
maximum was 4 drugs per prescription. Patients receiving 3 and 4 drugs per prescription were 6035 $(75.1 \%)$ and $1122(14 \%)$ respectively (Table 2$)$.

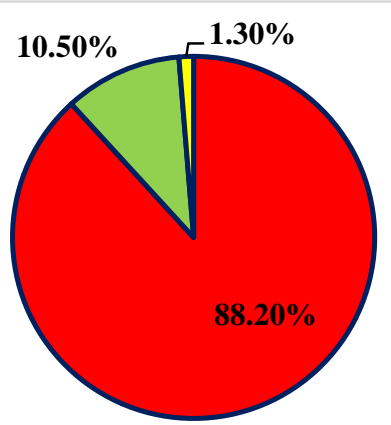

DOral $\quad$ Topical $\quad$ Parenteral

Figure 1: Routes of drug administration.

Table 2: Number of drugs per prescription.

\begin{tabular}{|lll|}
\hline $\begin{array}{l}\text { Number of drugs } \\
\text { per prescription }\end{array}$ & $\begin{array}{l}\text { Number of } \\
\text { prescriptions }\end{array}$ & $\begin{array}{l}\text { Percentage } \\
(\%)\end{array}$ \\
\hline 1 & 20 & $0.3 \%$ \\
\hline 2 & 851 & $10.6 \%$ \\
\hline 3 & 6035 & $75.1 \%$ \\
\hline 4 & 1122 & $14 \%$ \\
\hline Total & $\mathbf{8 , 0 2 8}$ & $\mathbf{1 0 0}$ \\
\hline
\end{tabular}

Antimicrobials were the most commonly prescribed drugs (28\%), followed by antihistamines (25\%), antipyretics $(20.5 \%)$ and analgesics $(3 \%)$. The vitamin supplements $(2 \%)$; steroids $(1 \%)$ and miscellaneous drugs were prescribed in $18 \%$ of the patients (Figure 2).

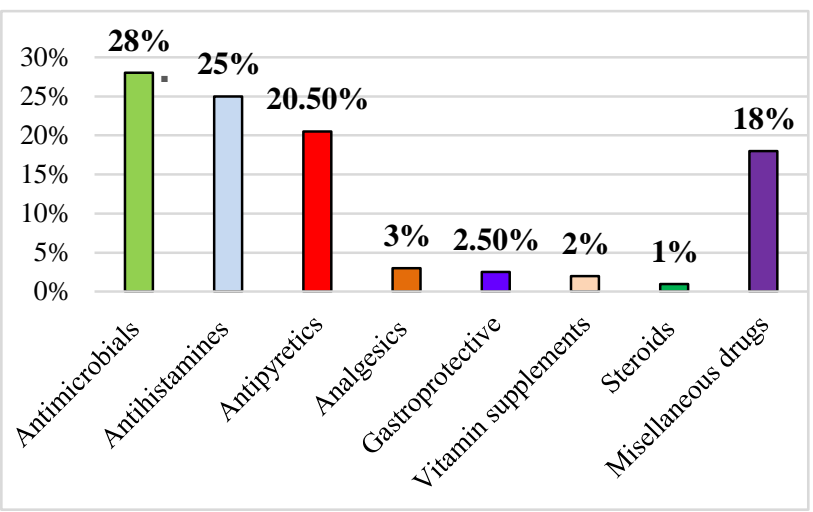

Figure 2: Commonly prescribed class of drugs.

Antimicrobial agents were prescribed to majority of the patients. Among them $\beta$ lactams (cephalosporins and pencillins) were prescribed maximally $68 \%$, followed by fluoroquinolone $26.5 \%$ (ciprofloxacin), macrolides $0.7 \%$, antiprotozoal $4.5 \%$, and antifungal $0.3 \%$. Antibiotics were given for 3 days only as per hospital guidelines, with follow-up treatment in subsequent visit (Table 3).
Table 3: Most common antimicrobials used.

\begin{tabular}{|lll|}
\hline $\begin{array}{l}\text { Antimicrobials } \\
\text { prescribed }\end{array}$ & $\begin{array}{l}\text { Number of } \\
\text { antimicrobials }\end{array}$ & $\begin{array}{l}\text { Percentage } \\
(\%)\end{array}$ \\
\hline$\beta$ lactams & 3999 & $68 \%$ \\
\hline Fluoroquinolones & 1556 & $26.5 \%$ \\
\hline Macrolides & 40 & $0.7 \%$ \\
\hline Antiprotozoal drugs & 274 & $4.5 \%$ \\
\hline Antifungal drugs & 17 & $0.3 \%$ \\
\hline Total & $\mathbf{5 8 8 6}$ & $\mathbf{1 0 0}$ \\
\hline
\end{tabular}

Table 4: Number of prescriptions in generic/ brand names.

\begin{tabular}{|ll|}
\hline Prescription parameter & Numbers (\%) \\
\hline Drug prescribed by generic name & $18224(86.5 \%)$ \\
\hline Drug prescribed by brand name & $2834(13.5 \%)$ \\
\hline Total & $\mathbf{2 1 0 5 8}$ \\
\hline
\end{tabular}

Majority of the drugs were prescribed by the generic names $(86.5 \%)$ and prescribed by brand names was $13.5 \%$ (Table 4). Prescriptions were lacking in various parameters like chief complaint $(3.1 \%)$, duration of treatment $(1.5 \%)$, frequency of doses $(1.6 \%)$ and dosage forms $(0.9 \%)$ (Table 5). In our study, a single antibiotic was prescribed to $5792(72.1 \%)$ patients and two antibiotics were prescribed to $94(1.1 \%)$ patients and $2142(26.6 \%)$ patients did not receive the antibiotics in their prescription (Table 6).

Table 5: Adequacy of prescription parameters.

\begin{tabular}{|lll|}
\hline Prescription & \multicolumn{2}{l|}{ Number of prescriptions } \\
\hline parameters & Mentioned & Not mentioned \\
\hline Chief complaints & $7773(96.9 \%)$ & $255(3.1 \%)$ \\
\hline Frequency of doses & $7898(98.5 \%)$ & $130(1.5 \%)$ \\
\hline $\begin{array}{l}\text { Duration of } \\
\text { treatment }\end{array}$ & $7905(98.4 \%)$ & $123(1.6 \%)$ \\
\hline Dosage form & $7952(99.1 \%)$ & $76(0.9 \%)$ \\
\hline
\end{tabular}

Table 6: Number of antimicrobials per prescription.

\begin{tabular}{|lcl|}
\hline $\begin{array}{l}\text { Number of } \\
\text { antimicrobials per } \\
\text { prescription }\end{array}$ & Prescription & $\begin{array}{l}\text { Percentage } \\
(\%)\end{array}$ \\
\hline 1 & 5792 & $72.14 \%$ \\
\hline 2 & 94 & $1.17 \%$ \\
\hline No antimicrobials & 2142 & $26.69 \%$ \\
\hline Total & $\mathbf{8 0 2 8}$ & $\mathbf{1 0 0}$ \\
\hline
\end{tabular}

The most common type of infection was seen in ear $(39.5 \%)$, followed by throat $(35.5 \%)$ and nose $(25 \%)$. Among the ear infections, most common was otitis media (1114), followed by otitis externa (814) and impacted wax (656). Among throat infections, most common was pharyngitis (1054), followed by tonsillitis (837) and in nose infections, most common was sinusitis (896), followed by rhinitis (536). 
The other drugs which were prescribed along with antibiotics to produce symptomatic relief were antihistamines (chlorpheniramine, citirizine), antipyretics (paracetamol), analgesics (diclofenac, aceclofenac), antacids (ranitidine, omeprazole) and steroids.

\section{DISCUSSION}

The present descriptive study indicates the general trends of drug prescribing among out patients Department of Otorhinolaryngology.

In this study, male patients were higher than female patients. This was similar to study conducted by Sridevi SA et al showing male predominance $(65 \%)$ than female (35\%) and also similar findings were seen in the study conducted by Pradhan et al. ${ }^{18,19}$

Our study showed that majority of the patients were between the age group of 18-40 years, followed by 41-60 years and lowest percentage was seen in geriatric patients, indicating that most of the ear, throat and nose infections were common among adults. Similar findings were reported by study done by Ain et al. ${ }^{9}$

The prescription index in our study was 2.6 , whereas study done by WHO in India-Karnataka (2002) was between 3-3.5. Majority of patients had received 3 drugs per prescription constituting $70.1 \%$, followed by 4 drugs per prescription constituting 14\%. A study which was done by Padwal et al showed that average number of drugs per prescription was four. ${ }^{20}$

In our study, it was found that most of the drugs were prescribed in generic names rather than brand names, as the physicians were aware of low cost of generic drugs and also keeping in mind that in government set up most of the patients were from low socioeconomic status. Use of generic drugs is helpful in decreasing cost of therapy and avoiding medication errors. Whereas study conducted by Padwal et al, showed that most of the drugs were prescribed by brand names rather than the generic names. $^{20}$

Our study showed among the different class of drugs, most commonly prescribed drugs were antimicrobials (28\%), followed by antihistamines $25 \%$. Most common antibiotics prescribed were $\beta$ lactams (Pencillins and cephalosporins), followed by fluoroquinolones. Our study showed that unwanted broad spectrum antimicrobials, newer and costly antimicrobials were not prescribed. The study conducted by Farhan AK et al and another study done by Nitasha Bhat GM et al have shown that $\beta$ lactams were the most commonly prescribed antibiotic. $^{21,22}$ In this study, the most common antihistamine $\left(\mathrm{H}_{1}\right.$ blocker $)$ prescribed was chlorpheniramine. A study done by Padwal et al, revealed similar findings like Antimicrobials (24.8\%), NSAIDs $(23.6 \%)$, gastroprotective $(22.5 \%)$, antihistamines $(19.9 \%)^{20}$
The concomitant use of medications prescribed were antihistamines, antipyretics and analgesics to relieve the nasal congestion, fever and pain respectively.

Vitamin supplements like B-complex and vitamin C were given to reduce mouth ulcer and also to patients who are on chronic treatment with antibiotics.

Gastroprotective drugs were administered, mainly the $\mathrm{H}_{2}$ blockers (ranitidine) and proton pump inhibitors (omeprazole) to prevent the gastro oesophageal reflux and drug induced gastritis. Majority of the drugs prescribed were from the National list of Essential medicines, India.

Majority of the drugs were administered by oral route followed by topical route, similar findings were seen in study done by Padwal et al. ${ }^{20}$

Our study showed that the most common type of infection affected the ear like otitis media, otitis externa and impacted wax, followed by throat infection such as pharyngitis, tonsillitis laryngitis and nose infection such as sinusitis, rhinitis and epistaxis. Drug consumption in percentage was highest among ear infection as number of cases were high, followed by throat infection and nose infection. This is similar to the study conducted by Yadav et al showing higher incidence of ear infection (50.8\%), followed by throat infection $(31.3 \%)$ and least were nose infection $(26.4 \%)$. Similar findings were seen in study done by Nitasha Bhat GM et al and Sathiya SB et al and Ayan et al, in their study revealed that higher prevalence was seen in ear disease $89(40.8 \%)$, followed by throat disease $72(33.03 \%))^{3,21-23}$

Our study had certain limitations, like there was lack of information about definite bacterial etiology and prevalent organisms which could have affected the result of study. Since the study was done in a government hospital having limited supply of drugs, the results cannot be compared with private hospitals and our study could not explore the adverse effects of the drugs prescribed.

\section{CONCLUSION}

The present study showed that among antimicrobial agents, $\beta$ lactams were the commonly prescribed drugs in the Department of Otorhinolaryngology. Maximum number of cases was diagnosed with ear infections and majority of the drugs were prescribed orally. Prescription or drug use study acts as a tool to give feedback to clinicians regarding over or under prescription of drugs, cost-benefit analysis, and rational drug use.

\section{ACKNOWLEDGEMENTS}

Authors would like to thank the faculty and patients for participating in the study. 
Funding: No funding sources

Conflict of interest: None declared

Ethical approval: The study was approved by the Institutional Ethics Committee, MIMS, Mandya

\section{REFERENCES}

1. Jain S, Upadhyaya P, Goyal J, Kumar A, Jain P, Seth $\mathrm{V}$ et al. A systematic review of prescription pattern monitoring studies and their effectiveness in promoting rational use of medicines. Perspect Clin Res. 2015;6(2):86-90.

2. Dukes MNG. Drug Utilization Studies; General Background. Edited by Laporte JR, Baksaas I, Lunde PKM. WHO Regional Publications, European Serious; No. 1992;45:16-8.

3. Pramila Y, Vanita K, Preety L, Siddhartha J. Drug utilization trends in ENT out patient department in a teaching hospital. Int $\mathbf{J}$ of Pharma and Bio Sci. 2010;1(4):153-60.

4. Goud SK, Kumar TR, Patil VG, Anup BA, Rajlakshmi KH, Senpaty S et al. Incidence and Drug use in Chronic Suppurative Otitis Media (CSOM) in outpatient department of E.N.T at teritiary care teaching hospital. IOSR-JDMS. 2014;13(4):13-9.

5. Goel RK, Bhati Y, Dutt HK, Chopra VS. Prescribing pattern of drugs in the outpatient department of a tertiary care teaching hospital in Ghaziabad, Uttar Pradesh. J App Pharm Sci. 2013;3(4,1):S48-51.

6. Alam K, Mishra P, Prabhu M, Shankar PR, Palaian S, Bhandari RB et al. A study on rational drug prescribing and dispensing in outpatients in a tertiary care teaching hospital of Western Nepal. KUMJ. 2006;4(16):436-43.

7. Suman RK, Kumar R, Garje AY, Wagh AR, Satpathy A, Ray IP. Drug Usage Patterns in ENT Out Patients Department of Teaching Hospital. IJSR. 2014;3(7):341-3.

8. Jain N, Lodha R, Kabra SK. Upper respiratory tract infections. Indian J Pediatr. 2001;68:1135-8.

9. Ain MR, Shahzad NAM, Alam MS, Khanam R. Drug utilization pattern of antibacterials used in ear, nose and throat outpatient and inpatient departments of a University Hospital at New Delhi, India. J Pharm Bioall Sci. 2010;2(1):8-12.

10. Ramachandra K, Sanji N, Somashekar HS, Acharya A, Sagar JK, Halemani SS. Trends in prescribing antimicrobials in an ENT outpatient department of a tertiary care hospital for upper respiratory tract infections. Int J Pharmacol and Clin Sci. 2012;1:15-8.

11. Guru Prasad NB, Dhananjay K, Rajasekhar CH, Rajesh D, Raghavendra AY, Vinodraj K et al. A study of prescription pattern of antimicrobial usage in Ear, Nose and Throat infections of a rural teaching hospital. J of Evolution of Med and Dent Sci. 2014;3(60):13407-14.

12. Dhanasekharan SV, Rajaram S, Jayan M, Sargunan A, Shankar R. Trends of antimicrobial prescription in
Department of Otorhinolaryngology in a teritiary care teaching hospital. Med. Res. Chron. 2015;2(1):44-50.

13. Naik HG, Chitra C, Khanwelkar CC, Kolur A, Desai R, Gidamudi S. Drug utilization study on antibiotics use in lower respiratory tract infection. Natl J Med Res. 2013;3(4):324-7.

14. Pallavi I, Roshani S, Amita S, Prabhakar S. Prescribe Pattern of drugs and antimicrobials preferences in the Department of ENT at tertiary care SGM Hospital, Rewa, MP, India. J Pharm Biomed Sci. 2016;6(1):8993.

15. Sachdeva PD, Patel BG. Drug utilization studiesscope and future perspectives. Int $\mathbf{J}$ of Pharma Bio Res. 2010;1(1):11-7.

16. Lisha JJ, Cherian M, Sreedharan J, Cherian T. Patterns of antimicrobial therapy in acute tonsillitis: A cross-sectional Hospital-based study from UAE. An Acad Bras Cienc. 2014;86(1):451-7.

17. Sridevi SA, Janagan A, Rathnasamy P, Rajarajeswari R. Drug utilization study in the otorhinolaryngology department in a tertiary care hospital. Int J Basic Clin Pharmacol. 2013;2(3):306-10.

18. Pradhan S, Jauhari AC. A study of antibiotics used in adult respiratory disorders in Kathmandu and Bhaktapur. Nepal Med Coll J. 2007;9:120-4.

19. Padwal SL, Kulkarni MD, Deshmukh VS, Patil JR, Jadhav SS, Jadhav AD. Drug use pattern in the ear, nose, throat outpatient department of a rural tertiarycare teaching hospital. Natl J Physiol Pharma Pharmacol. 2015;5:212-6.

20. Khan FA, Nizamuddin S, Tariq SM. Patterns of prescription of antimicrobial agents in the Department of Otorhinolaryngology in a tertiary care teaching hospital. African J Pharmacy Pharmacol. 2011;5:1732-8.

21. Bhat GM, Holla R, Kamath PSD. A study of prescription pattern in the drug therapy of ear, nose and throat infections at a tertiary care hospital in Mangalore. Int J Basic Clin Pharmacol. 2015;4:68690.

22. Sathiya SB, Panchasara AK, Barvaliya MJ, Jha SG, Tripathi CB. Drug utilization pattern of antimicrobial agents in an outpatient department of otorhinolaryngology in a tertiary care hospital: a prospective, cross-sectional study. Int J Basic Clin Pharmacol. 2016;5:65-9.

23. Ayan P, Bhowmick S, Basu J, Chattopadhyay R, Paul S, Sumit C. Study on prescribing pattern of antimicrobials in ENT department of a tertiary care teaching hospital in Bihar, India. WJPR. 2015;4(8):1839-52.

Cite this article as: Sumalatha R, Nagabushan $\mathrm{H}$, Prasad HM. Drug utilization study in otorhinolaryngology outpatient department in a tertiary care teaching hospital. Int J Basic Clin Pharmacol 2017;6:572-6. 